\title{
Economic Statistics: How to Become Lean and Mean?
}

\author{
Peter van de Ven $^{1}$
}

\begin{abstract}
The compilation of official statistics has changed dramatically over the past decades, and it will continue to change. These changes not only relate to user demands; also the source data and the means, in the sense of the technologies available for compiling statistics, have undergone and will continue to undergo significant changes. This article addresses the main developments and challenges in relation to the sources for compiling official statistics (input), the technologies for processing data (throughput), and the user demands (output) for official statistics. It is concluded that all these changes have, and continue to have, a significant impact on the way statistics are compiled, and the article puts forward a number of suggestions for the future direction of compiling official statistics.
\end{abstract}

Key words: Statistical system; national accounts; micro macro linkage; statistical units.

\section{Introduction}

The compilation of official statistics has changed dramatically over the past decades, and it will continue to change. Users demand more detailed, more interrelated and timelier data. In addition, the source data and the means, in the sense of the available technologies for compiling statistics, have undergone and will continue to undergo significant changes. More generally, producers of official statistics have to face various challenges. Many national statistical offices are facing serious budget cuts, or at least need to increase their efficiency and effectiveness in compiling statistics. In many countries, there are strong pressures to decrease the respondent burden from statistical surveys. On the other hand, there is an unprecedented abundance of data in present-day society. Moreover, private and not-for-profit organisations compile and disseminate statistics on their own, and statistical offices need to define their place in this new environment, and need to think again about their competitive edge. The question is how to address these challenges. What is the best way forward in compiling statistics?

This article starts, in Section 2, by describing the main developments and challenges in relation to the sources for compiling official statistics (input). This mainly concerns the gradual move from the use of survey-based data to so-called administrative data sources. Subsequently, Section 3 dwells on the effects of technological developments in the processing of data (throughput). Section 4 then deals with the main changes in user demands (output). Here, the major topics being discussed are: the nexus of productivity,

${ }^{1}$ OECD - Statistics 4, rue André Pascal Paris 75775, France. Email: Peter.VANDEVEN@ oecd.org.

Acknowledgments: The views expressed herein are those of the author and should not be attributed to the Organisation of Economic Co-operation and Development. The author is accountable for any mistakes in this article. 
knowledge capital and trade; accounting for risks and vulnerabilities; distributional issues; well-being and sustainability; and last but certainly not least, globalisation.

The article concludes, in Section 5, with a summary of the main issues in relation to the compilation of official statistics. This section also puts forward a number of suggestions for the future direction of compiling official statistics, without having the intention of putting forward an all-embracing, final solution to all problems.

\section{Input}

One of the main input challenges comes from the continuing pressure to decrease the respondent burden. Respondents, individuals and enterprises alike, usually don't get particularly excited about being selected into the sample for a certain statistical survey. Although politicians would like to have high quality statistical output to monitor and analyse the latest developments, they are also very prone to societal pressures to limit the burden from surveys, especially when they come from enterprises arguing that the surveys add to their costs and thus have a negative impact on their productivity and cost effectiveness. But then again, how good are the source data that can be derived from statistical surveys? One can have some doubts here. It is usually possible to measure and adjust for sampling and certain other errors, but to estimate the errors related to the improper interpretation of the requested definitions is much more questionable, in particular if data according to these definitions cannot be mapped one to one to business records. Moreover, how often is the completion of a survey taken seriously, and not left to the most junior staff member or intern within the company of the respondent? Direct comparisons between certain source statistics and national accounts aggregates often show major discrepancies. Take, for example, household receipts of property income which can also be tracked by looking at the counterparty sectors paying the relevant income. Income surveys of households usually show remarkably lower estimates; in some countries a number of transactions, especially the ones related to property income and entrepreneurial income, have coverages as low as $10-20 \%$ (see Zwijnenburg 2016). This may be caused by under-representation of the rich and famous, but a major part is probably also caused by (deliberate) under-reporting, for example related to missing one-off receipts like dividends and interest.

Whereas the future of surveys looks very bleak, the use of administrative records from public administrations and private enterprises looks bright. The availability of administrative data is continuously increasing, and the knowledge, techniques and IT tools to process them efficiently are becoming more readily available. However, the population and the definitions of the variables in these databases may not always be fully consistent with what official statistics tries to capture. In addition, the changeover to administrative records may require extensive validity checks on the quality and appropriateness of these databases. But, once validated, the shortcomings are usually well known and can be adjusted for. National statistical offices also recognise the potential of these data sets, as well as the importance of having influence on the set-up or modification of these records to make them better suitable for statistical purposes.

There is also Big Data, usually written with capital letters, the latest buzzword. Here, it is important to make a distinction between structured data, such as private records that are 
being collected as part of an administrative process (e.g., scanner data of sales by supermarkets or the underlying databases of housing websites), and unstructured data, such as data derived from scraping the internet to detect certain phenomena. Enhanced use of available structured data sets looks very promising, as they are usually well-defined in terms of population and concepts; the main problems in using them are related to getting regular access to them, and influencing their content in order to avoid, for example, discontinuities over time. On the other hand, scraping the internet certainly has potential, for example in nowcasting certain phenomena for which the plausibility of the applied methodology has proven to be accurate, or for the collection of price data. However, one has to recognise that problems in this area can be multi-fold: representativeness of the observations, having continuous access to the relevant websites, consistency of the methodology over time given the quick changes in the environment, etc. Nevertheless, as stated, it can create interesting opportunities.

With regard to collecting data, there are other problems as well. In the area of economic statistics, in particular, one can observe much more volatility in the goods and services produced, including the technologies to produce them. In addition, the organisational arrangements are continuously changing, even moving parts of the production process across borders.

Whatever the case, the statistical community recognises more and more that the availability of massive amounts of data from public and private records can provide great opportunities to produce statistics with greater granularity, and thus may be able to address quickly evolving user demands for more detailed analysis. However, this also requires further efforts to enhance the accessibility of the relevant databases, including the establishment of legal arrangements and the continuous engagement with owners/ producers of the relevant public and private databases. It may also require further thinking about the statistical units that are being used in the compilation of official statistics. Not only criteria concerning the statistical purity of the concepts of statistical units, but also practical considerations with respect to the availability of and the opportunities for linking the various source data, should increasingly feed into the decision process. This issue of statistical units will be addressed later on in this article.

\section{Throughput}

In the past decades, ICT capabilities to process data have increased enormously, and will continue to do so. However, the potential of computerised handling of information has and will have much broader implications. Nowadays, it is much easier to process vast amounts of data, to process and link the various large administrative registers. However, that is true for others as well, as a consequence of which producers of official statistics will have to face more and more competition from other organisations, private as well as public, that have access to large data sets (see, for example, UNECE 2017). Facing this competition and thinking about the competitive edge of official statistics goes beyond simply stating that official statistics are compiled according to certain quality standards, and thus are a safe haven. There is a clear need to improve the potential for flexibility to quickly meet evolving user demands in a more timely fashion. There is also a need to reap the benefits of potential efficiency gains, certainly with ongoing pressures on public budgets 
for official statistics. In this respect, one could say that standing still is equivalent to going backwards.

Present and future technology can also provide ample opportunities for developing and maintaining a much more transparent process design for statistics, enabling more transparent linkages between macro-statistics and underlying source data, thus enhancing the flexibility of the statistical system. This may need some further explanation, by way of using the example of economic statistics.

The process of producing economic statistics can be broken down into three major steps. It starts with the business register, the main goal of which is to have a complete and up-todate statistical register of all enterprises and other institutions on the economic territory. This register is subsequently used to derive samples for surveys, and/or to link various administrative data sources. The next step concerns the compilation of statistics on a variety of industries, sectors and/or specific economic variables, such as foreign trade and investments. Using these and other sources, in a final step, national accounts try to produce a consistent macro-economic picture.

In the process of compiling national accounts, the source data are changed for a number of reasons, the most significant ones being (i) adjustments to the definitions according to international standards (SNA 2008 and ESA 2010; see United Nations et al. 2009 and European Commission 2013, respectively) (ii) adjustments for incompleteness, for example hidden activities; (iii) adjustments for inconsistencies of source statistics over time, due to the primary goal of national accounts to arrive at consistent time series data; and, last but certainly not least, (iv) adjustments because of balancing the whole system to arrive at a consistent set of data. In the process, often the connection between the national accounts aggregates and the underlying source statistics is, to say the least, not very transparent and well documented, for outside users as well as internal users.

The above lack of documentation clearly hampers the possibilities to drill down to more granular data, a request often voiced by researchers who would like to analyse, for example, productivity developments by (groups of) enterprises with certain characteristics, to analyse the contributions of various types of enterprises to output, value added and employment, or to analyse income, saving, investment and finance for different sets of corporations. It also seriously limits the flexibility of the statistical system, in the sense that it is quite difficult and resource-demanding to quickly and efficiently respond to changing user demands requiring alternative breakdowns of national accounts data.

\section{Output}

In this section, a number of issues related to output are addressed. As the author of this article is a lifelong addict to national accounts, it may not come as a surprise that this is first and foremost done from the perspective of national accounts. In doing so, before discussing a number of specific examples, some of the main trends in user demands are discussed.

First of all, one is nowadays confronted with more quickly evolving demands. Yesterday, it was all about the causes and the impacts of the Great Recession at the end of the 2000s, including ways to avoid such crises in the future. Today, the focus is on explaining the productivity slowdown, the role of knowledge-based capital and the 
digitalisation of the economy. Tomorrow, the focus may be turned (more prominently) to issues related to the ageing society and sustainability.

Another characteristic of present-day user demands is that they are much more specific. In a way, it is the end of generic macro-economic policy, as observed in the 1960s, 1970s, and 1980s. Today's research and policy analysis relate to more specific questions requiring more detailed data according to certain sets of definitions and rather specific views on the economy and society. Whatever the case, more granularity is often at the heart of the requests, probably also triggered by the improved computing power of researchers and analysts.

Another more structural development in the user demands is related to requests for more integrated data. It is not the economy, per se, that raises the interest of policy analysts and researchers. Understanding the interrelations, the win-wins and the trade-offs, between different areas of concern becomes more prominent. Examples relate to the interrelationship between economic developments and environmental sustainability or well-being more generally, not only today, but also the sustainability of well-being in the future. These types of analysis obviously require underlying data sets, in which the various areas of interest are linked to each other, and the relevant data are internally consistent with each other.

A final point concerns the timeliness of statistics. Whereas 30-40 years ago, annual data, available 6-7 months after the end of the reference year, would be considered satisfactory in many cases, nowadays, the focus lies on quarterly and monthly data, available within a quarter or a month after the reference period. This continuing pressure to improve timeliness is not expected to stop over the next couple of years.

In the remaining part of this section, five specific areas will be addressed, by way of examples to better understand the future developments in user demands: (i) the nexus of productivity, knowledge capital and trade; (ii) accounting for risks and vulnerabilities; (iii) distributional issues; (iv) well-being and sustainability; and last but not least, (v) globalisation.

\section{(i) Productivity, Knowledge Capital and Trade}

An important set of policy questions is related to enhancing growth and trying to explain the productivity slowdown. What is the role of knowledge-based capital, and do we measure it appropriately? Do we capture the impact of the digitalisation of the economy and society at large appropriately? For developed economies, and more and more for developing countries as well, intellectual property products are a key driver for competitiveness, productivity growth, or more generally growth in the income-generating capacity of an economy.

All of this is also reflected in the international standards for national accounts, the 2008 System of National Accounts (SNA). While the 1993 version of the SNA (United Nations et al. 1993) already made a major step forward with the recognition and recording, as assets, of (i) mineral exploration and evaluation, (ii) computer software and databases, and (iii) entertainment, literary and artistic originals, the 2008 SNA extended this further with the inclusion of expenditures on research and development (R\&D) as investments. However, there are several pleas for going beyond those categories. In Corrado et al. 
(2005, 2009), for example, a call is made to include all “. . . business expenditures aimed at enhancing the value of a firm and improving its products, including human capital development as well as $R \& D$. . ..”.

The 2008 SNA has also been struggling with the asset boundary, as can be derived from its research agenda, which includes a special subsection on broadening the fixed asset boundary to include other intellectual property assets; see United Nations et al. (2009), paragraphs A4.52-55. Three possible extensions are explicitly mentioned: (i) innovation (going beyond the currently included R\&D assets by also including expenditures made by production and engineering departments in identifying new products, and also expenditures related to market research to determine the demand for a new product, and marketing expenditures to promote the new product); (ii) marketing assets (brand names, mastheads, trademarks, logos and domain names); and (iii) human capital.

All in all, one can conclude that many research and policy questions are related to the role of intangible assets in the economy. Answering some of these questions requires much more detailed data on expenditures related to knowledge in the domain of national accounts. Other questions concern the role of various enterprises and/or government in creating growth, or enhancing productivity growth. Are large enterprises more productive than small/medium sized enterprises, or are the latter companies the main drivers of growth? What is the impact of globalisation? Are internationally operating enterprises more productive than nationally operating enterprises? What is the role of trade and foreign direct investment? What are possible spill-over effects of engaging in the global economy? All of this obviously requires much more granularity and the linking of macroeconomic data with the underlying micro data from business statistics and foreign trade.

\section{(ii) Risks and Vulnerabilities}

In the aftermath of the economic and financial crisis, the question arose whether we missed something in our statistics, whether the availability of certain statistics would have allowed for better monitoring and analysing the build-up of risks, such as those related to asset price bubbles. In addition, the spreading of the crisis, which started in the US housing market, to a global crisis with defaults of financial corporations all over the world, negative growth rates, and subsequent problems in government finance raised questions about whether or not these phenomena are adequately captured in available statistics. In response, the G-20 Data Gaps Initiative, based on an analysis by the International Monetary Fund (IMF) and the Financial Stability Board (FSB), was endorsed by the G-20 Finance Ministers and Central Bank Governors. This initiative contained 20 recommendations to improve the monitoring of risks and vulnerabilities. For more details on the G-20 Data Gaps Initiative, see for example IMF (2009) and Bese Goksu and Van de Ven (2015).

Many of the recommendations are related to financial corporations and financial markets, but certainly not exclusively. Furthermore, the monitoring of possible risks building up in government, households and non-financial corporations is part of the exercise. Having a complete picture of developments in income and finance in the institutional sector (non-financial corporations, financial corporations, general government, households, non-profit institutions serving households, and the rest of the world) on 
a quarterly basis, that is, compiling the so-called (institutional) sector accounts, is perhaps the single most important recommendation, bringing together many of the other individual recommendations, thus serving as a kind of umbrella. More generally, one can note an increased interest in developments of income and finance, where 30-40 years ago policy was much more focused on analysing the production of goods and services, including the income generated through this process.

Looking more specifically at monitoring risks and vulnerabilities, data requests are related to, for example, capturing currency and maturity mismatches through more detailed breakdowns of the various financial instruments by currency and (original and remaining) maturity. To capture credit default risk and the exposure to certain countries and sectors, so-called "from-whom-to-whom" tables are being developed, which track the counterparty sectors of loans and securities held by the various sectors, thus also enabling analysis of potential spill-over effects of defaults. Better monitoring of "shadow banking", that is, capturing new developments in financial intermediation, by having more detailed sector breakdowns of financial corporations, is also part and parcel of the G-20 Data Gaps Initiative. Again, central themes in user demands are more granularity, more integration, and improved timeliness.

\section{(iii) Distributional Issues}

"Every American should have above average income, and my Administration is going to see they get it" is assumed to be said by an American president on campaign trail. That may be very hard to achieve, but it is clear that the distribution of income, consumption and wealth is very high on the policy agenda, certainly after the record-breaking success of the "Capital in the Twenty-First Century" by Thomas Piketty (Piketty 2014). It is not only an issue in economic terms, but in other areas, such as access to health and education, distributional issues are also an important concern too. The main question is how to arrive at an economic growth that benefits all people in society - how to arrive at an inclusive growth.

These distributional issues first and foremost concern a much more detailed monitoring of developments of income, final consumption, savings and wealth for various groups of households. Considerable work is being done in this area, both within countries and in international organisations, such as the ECB, Eurostat and the OECD. The primary goal is to collect more granular data on households, and to try to link the results from surveys and administrative data to the relevant aggregates in national accounts. However, it also affects the compilation of enterprise statistics. To better understand developments in the distribution of income and wealth, one needs to start looking at the distribution of income generated by production, for example to capture the longer term impact of globalisation on the composition of economic activities in an economy, and how this affects the wage rates and the type of jobs in a country. Again, one can observe the need for more granularity, more specific research topics, and also pressure to improve the timeliness of statistics.

\section{(iv) Well-Being and Sustainability}

Although macro-economic indicators on economic growth are still driving government policy to a large extent, these economic developments by themselves cannot be on a par 
with changes in well-being, or welfare, and sustainability. This is also well recognised by the 2008 SNA (paragraph 1.75): "GDP is often taken as a measure of welfare, but the SNA makes no claim that this is so and indeed there are several conventions in the SNA that argue against the welfare interpretation of the accounts."

One of the most influential initiatives with a better understanding of well-being is the "Report by the Commission on the Measurement of Economic Performance and Social Progress" by Joseph Stiglitz, Amartya Sen and Jean-Paul Fitoussi (Stiglitz et al. 2009). The report contains various recommendations, among which five directly related to economic statistics. The main thrust of these five recommendations is to not only look at Gross Domestic Product (GDP), but also at household disposable income, the distribution of income and wealth, and the free services provided by unpaid household activities (taking care of children and elderly people, cooking meals at home, cleaning, etc.). This requires, among others, linking income and finance to the process of production and income generation, and giving much more attention to other indicators than economic growth alone; see, for example the OECD Dashboard on Households' Economic Wellbeing: http://www.oecd.org/std/na/household-dashboard.htm. It also requires linking micro data on distributional issues with macro-aggregates, as discussed above.

Importantly, the report does not contain a recommendation to objectively capture wellbeing in a single metric, by, for example, monetising all aspects that contribute to, or negatively impact, well-being. The same holds for trying to capture (environmental) sustainability by trying to monetise all negative externalities from economic activities on the environment. Well-being is considered to be a multi-dimensional phenomenon, and preference is given, at least for the time being, to defining the various aspects that constitute well-being, and then selecting indicators to monitor the developments for each of these aspects. An important example of this approach to capturing well-being is the OECD Better Life Index (see http://www.oecdbetterlifeindex.org/), in which eleven aspects, such as income, safety, trust, employment, health, and education, are monitored by a dashboard of indicators.

Given the above, the next logical step is to better monitor and understand the interrelations between the various aspects of well-being, to understand the trade-offs and the win-wins between the various domains. For example, what is the relationship between the output of the medical industry and the health outcomes of people, and how does this affect government finance, etc.? How to improve health outcomes? Should we spend more money on prevention, on the development of pharmaceuticals, on improving medical techniques, and how much money are we willing to expend? In efforts to answer this type of questions, linking of business statistics on the medical industry, very granular administrative data on treatments, government finance and national accounts can be considered to be a very promising way forward. This way of thinking and analysing related phenomena is actually very well developed in the area of environmental sustainability, where official international standards for linking economic developments with environmental issues have been endorsed by the UN Statistical Commission in 2012: the "System of Environmental-Economic Accounting (SEEA) 2012, Central Framework" (United Nations et al. 2014). Again, one can detect a need for more integrated data sets in specific areas of interest, a user demand for very granular data, and other similar issues. 


\section{(v) Globalisation}

Last but certainly not least, the phenomenon of globalisation is on the table, not only driving various policy and research questions, but also giving statisticians some serious headaches. More details on issues related to the (problems of) measuring and recording of globalisation-related phenomena can be found in UNECE, Eurostat, and OECD (2011) and UNECE (2015). However, the climax was reached with the vigorous debate that resulted from Ireland's remarkable growth rate of more than $26 \%$ in 2015 , which was the indirect effect of the relocation of activities of some multinational enterprises (MNEs) from one country to another; for a more extensive explanation, see OECD (2016).

In recent years, globalisation has indeed become an area of special interest to statisticians working on economic statistics, not only from an analytical point of view, but also related to the measurement of economic activities. As an example, Figure 1 shows the - sometimes - very large shares of economic activities controlled by foreign affiliates of MNEs. More generally, one can observe a continuing international fragmentation of production processes and outsourcing of activities, while the growing and quickly changing (legal and economic) arrangements further add to the complexity of compiling economic statistics. Moreover, there is ample evidence that the national allocation of value added and profits by MNEs is, for a significant part, driven by minimisation of global tax burden. This is done through mechanisms such as transfer pricing, channelling funds through Special Purpose Entities (SPEs), optimisation of the recording of the economic ownership and use of intellectual property products, and the allocation of costs related to corporate services more generally. Lipsey (2010) shows that the ratio of profits to compensation of employees of affiliates that are majority-owned by US MNEs ranges from 0.579 for affiliates in Europe to 11.709 for affiliates in the Other Western Hemisphere. Although it is clear that there is an economic rationale behind all of this, it hampers the analysis from an economic substance point of view, certainly when it comes to analysing national parts of MNEs.

The above may actually lead to serious problems in compiling statistics as a consequence of significant inconsistencies in the source data, at the national as well as the international level. When combining national data on, for instance, production, income

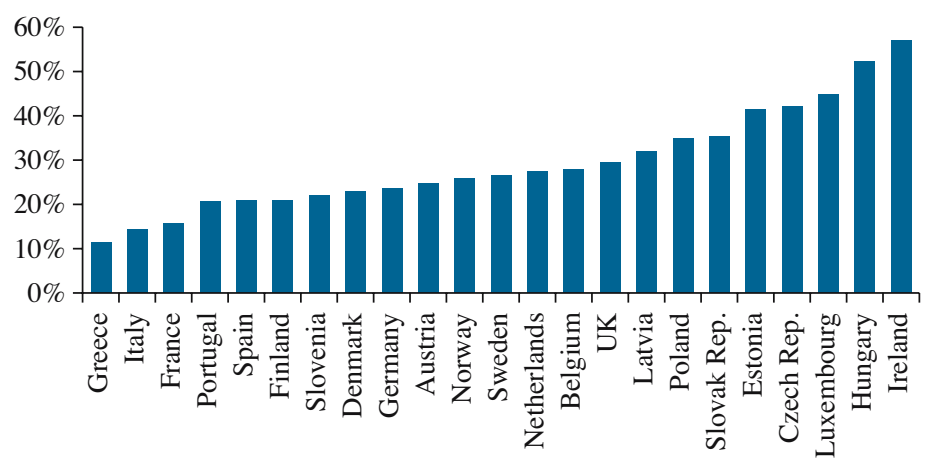

Fig. 1. Value added by foreign affiliates, \% of national total, 2013 (ISIC B-N, excluding K*). * All activities, excluding agriculture, forestry and fishing; financial and insurance activities; public administration; education; health; arts, entertainment and recreation; and some minor service activities. Source: OECD Trade in Value Added Database 
and finance, and foreign trade of a certain MNE, the relevant data may be so divergent that one may think that they relate to different enterprises. Inconsistencies can be so large that they even become noticeable at the macro-economic level. The same is true when one looks at the global level, which not only results in asymmetries in the foreign trade in goods and services, but also in foreign direct investment and other financial transactions and positions. More generally, it is far from certain that the nationally collected pieces of information on a MNE add up to the whole.

From a measurement perspective, it therefore becomes paramount to link the various source statistics on MNEs at the individual level - not just the ones related to production of goods and services, but also the source data on income and finance. Various national statistical offices have already set up special organisational units to monitor and analyse large and complex internationally operating enterprises. There is also a need for international profiling and exchange of (individual) data. The establishment of the Euro Groups Register is an excellent initiative in this field (see http://ec.europa.eu/eurostat/ statistics-explained/index.php/EuroGroups_register).

From an analytical perspective, separately distinguishing the activities, transactions and positions of multi-nationally operating enterprises - possibly further broken down into foreign controlled units and nationally controlled units - from nationally operating enterprises could definitely help in understanding economic developments. Moreover, one has to realise that resident parts of MNEs are only parts of a larger whole, as a consequence of which, at the national level, one is confronted with incomplete descriptions of the production process, income and finance. To fully understand the economic behaviour of MNEs, one may well have to monitor and analyse them at the global level.

Furthermore, when analysing the competitiveness of an economy, one tends to look at gross cross-border flows. This type of analysis also becomes flawed when one looks at global value chains, products for which the various parts of the production process are allocated to different countries, based on the competitive advantages of certain countries in performing certain functions in the production chain. Additional types of analysis, such as the OECD-WTO project on Trade in Value Added (TiVA), try to address these questions by looking at the value added content of trade flows instead of analysing gross cross-border flows. However, more granular supply and use tables, and input-output tables, are at the core of this analysis. Integration of various fields of (economic) statistics and granularity are again key words, in this case not only from user perspective, but also to get the measurement right. For more details, see, for example Ahmad and Ribarsky (2014).

\section{Conclusions and Way Forward}

In summary, when it comes to input and throughput, one can detect further pressure to reduce the respondent burden of enterprises and households, but the availability of administrative data from public and private sources, including the ability to process them, will create massive opportunities. Because user demands will continue to grow and evolve, and will require much more granular and integrated data, not to mention increased pressure for timeliness, national statistical offices will need to think of new ways to deal with these challenges. 
To effectively deal with the above challenges, one needs to address, in a rather "aggressive" way, some problems in the present-day compilation of official statistics, as these problems constitute important hurdles to the enhancement of the flexibility of the statistical system. These are hurdles that prevent us from arriving at greater consistency between various statistics, including consistency between micro data from source statistics and macro data from national accounts, and hurdles that prevent us from producing statistics with a greater timeliness.

Without having the goal of being complete, I consider two issues of particular importance. The first one concerns the use of different statistical units in the architecture of official statistics, basically coming down to the use of the (local) kind-of-activity unit or establishment in the statistics focusing on the production process, and the use of the enterprise (group) or institutional unit in the statistics describing income and finance. The other issue concerns the often observed silo type of approach in compiling statistics, with integration of the various source statistics at the macro-level (national accounts) only. The consequences are quite obvious: a less efficient compilation process, substantial inconsistencies between statistics, and considerable problems in linking the various statistics and maintaining the micro-macro linkage.

A strong plea is made here to view the statistical system as a whole, and develop a much more transparent process design for the compilation of (economic) statistics as a whole, from business registers to national accounts. In doing so, it is considered important to bring forward the integration of data, to make data consistent at the micro-level by setting up special organisational units to monitor and analyse large and complex internationally operating enterprises, and by linking administrative data sources at the level of the statistical unit for the remaining enterprises.

A reconsideration of statistical units may be instrumental in achieving the above goals. One should seriously reconsider the need of having various statistical units for describing the production process, and income and finance. In arriving at high quality official statistics, it may prove to be much more important to apply practical considerations than to aspire to conceptual purity in choosing statistical units. It may be preferable to use a statistical unit which provides maximum opportunities for linking various statistics at the micro-level and maximum opportunities for micro-macro linking. At the same time, a single statistical unit such as this may also prove to simplify the analysis of the nexus between production, income and finance. The most obvious choice for economic statistics may be the legal unit or the enterprise.

Bringing forward the linking and integration of data at the micro-level would also lead to improved linkage between source statistics and national accounts, as many inconsistencies would already be resolved at the micro-level, instead of during the balancing process within the system of national accounts. That being said, differences will continue to exist due to definitional divergences, estimates for hidden and illegal activities in national accounts, changes made to address inconsistencies over time, remaining balancing adjustments, and more. Here, it would be very beneficial to produce standardised "bridging tables", which explain the adjustments made during the process of compiling national accounts, and thus clearly show the linkages between macroaggregates and the aggregates that can be derived from (grossed up) micro-data. 
Furthermore, it is considered important "to keep it simple" when it comes to defining the system of official statistics. Stay, for example, closer to business accounting standards, and consider the compilation of national accounts in two steps. In the first step, data are balanced using definitions and concepts that are close to the ones collected at the level of enterprises, and only in a second step, adjustments are made to arrive at the internationally agreed set of definitions for macro-economic statistics. To arrive at a fully integrated set of statistics will not be feasible, but the above should create a better understanding of the links between the various data sets, and thus create enhanced possibilities for producers as well as users of official statistics to link micro data to macro data. As a consequence, the system, as such, would become more flexible to adapt to user demands.

In the 1980s and 1990s, there was something called the "Dutch School" in national accounts. The line of thinking of this school was to start from a national accounts system that stayed as close as possible to what could be observed, while the concepts and definitions would only be adapted at a later stage, to align it to economic theory. Perhaps it was too early for such a far-reaching view. Although, with the recent developments in input, throughput and output in mind, it may indeed provide the best way forward for the future development of official statistics.

\section{References}

Ahmad, N., and J. Ribarsky. 2014. "Trade in Value Added, Jobs and Investment." In Proceedings of the 33rd Global Conference of the International Association for the Research in Income and Wealth (IARIW), Rotterdam, August 24-30, 2014. Available at: http://www.iariw.org/papers/2014/AhmadPaper.pdf (accessed June 2017).

Bese Goksu, B., and P.J.M. van de Ven. 2015. "G-20 Data Gaps Initiative (DGI): A Second Phase.” The Statistics Newsletter of the OECD, No. 63, September 2015. Available at: http:// www.oecd.org/std/OECD-Statistics-Newsletter-September-2015.pdf (accessed June 2017).

Corrado, C., C. Hulten, and D. Sichel. 2005. "Measuring Capital and Technology: An Expanded Framework." In Measuring Capital in the New Economy, C. Corrado, J. Haltiwanger, and D. Sichel, 11-46. University of Chicago Press, ISBN: 0-22611612-3.

Corrado, C., C. Hulten, and D. Sichel. 2009. "Intangible Capital and U.S. Economic Growth.” The Review of Income and Wealth, Volume 55: 661-685. Doi: http://dx.doi.org/ 10.1111/j.1475-4991.2009.00343.x.

European Commission 2013. European System of Accounts - ESA 2010. Luxembourg: Publication Office of the European Union.

IMF and FSB 2009. The Financial Crisis and Information Gaps. Report to the G-20 Finance Ministers and Central Bank Governors. Available at: https://www.imf. org/external/np/g20/pdf/102909.pdf (accessed June 2017).

Lipsey, R. 2010. "Measuring the Location of Production in a World of Intangible Productive Assets, FDI and Intrafirm Trade." The Review of Income and Wealth, Volume 56: S99-S110. Doi: http://dx.doi.org/10.1111/j.1475-4991.2010.00385.x. OECD 2016. “Are the Irish $26.3 \%$ better off?" OECD Insights, 5 October 2016. Available at: http://oecdinsights.org/2016/10/05/are-the-irish-26-3-better-off/. 
Piketty, T. 2014. Capital in the Twenty-First Century. Cambridge, Massachusetts, London, England: The Belknap Press of Harvard University Press.

United Nations, European Commission, International Monetary Fund, Organisation for Economic Cooperation and Development, and World Bank 1993. System of National Accounts 1993. Brussels/Luxembourg, New York, Paris, Washington D.C.

United Nations, European Commission, International Monetary Fund, Organisation for Economic Cooperation and Development, and World Bank 2009. System of National Accounts 2008. New York.

United Nations, European Commission, Food and Agricultural Organisation, Organisation for Economic Cooperation and Development, International Monetary Fund, The World Bank Group 2014. System of Environmental-Economic Accounting 2012 - Central Framework. New York.

Stiglitz, J.E., Sen, A., and Fitoussi, J.-P. 2009. Report by the Commission on the Measurement of Economic Performance and Social Progress. Paris. Available at: http:// ec.europa.eu/eurostat/documents/118025/118123/Fitoussi+Commission + report (accessed June 2017).

UNECE 2015. Guide to Measuring Global Production. New York, Geneva.

UNECE 2017. "Value of Official Statistics: Recommendations on Promoting, Measuring and Communicating the Value of Official Statistics." In Proceedings of the sixty-fifth Plenary Session of the Conference of European Statisticians, June 19-21, 2017. Available at: http://www.unece.org/fileadmin/DAM/stats/documents/ece/ces/2017/ CES_4-Value_of_Official_Statistics_for_endorsement_for_upload.pdf (accessed June 2017).

UNECE, Eurostat, and OECD 2011. The Impact of Globalization on National Accounts. New York, Geneva.

Zwijnenburg, J. 2016. Expert Group on Disparities in a National Accounts Framework. Results from a Recent Exercise. Paris: OECD. (Working Paper No. 75, STD/DOC(2016)9).

Received January 2017

Revised June 2017

Accepted July 2017 